\title{
Interannual variability of the Equatorial Jets in the Indian Ocean from the merged altimetry data
}

\author{
Y.K. Somayajulu*a, V.S.N. Murty ${ }^{a}$, C. Neelima a ${ }^{a}$ P.S.V. Jagadeesh ${ }^{b}$ \\ National Institute of Oceanography, Dona Paula, Goa-403 004, India. \\ National Remote Sensing Agency, Hyderabad - 500 037, India.
}

\begin{abstract}
The merged ERS-1/2, TOPEX/Poseidon and Jason-1 altimeter weekly sea level anomalies (SLAs) for the period 19972005 were analyzed to study the variability of sea level and computed geostrophic currents in relation to the equatorial jets in the Indian Ocean. Year-to-year-variability in SLA was large (small) at $77^{\circ} \mathrm{E}\left(93^{\circ} \mathrm{E}\right.$ ) with a pronounced (weaker) semi-annual variation. The computed geostrophic currents, using the second order differential equation, in the equatorial region $\left(2^{\circ} \mathrm{S}-2^{\circ} \mathrm{N}\right)$ revealed the existence of spring and fall equatorial jets in each year, but with considerable variation. The 9 year mean (excluding 1997-98) SLA and the derived currents revealed that spring (fall) jet was weak (strong) with higher (lesser) magnitudes of SLA in the eastern basin. The computed surface currents agreed well with the Acoustic Doppler Current Profiler (ADCP) measured currents and OGCM for Earth Simulator (OFES) simulated currents. The interannual variability of the equatorial jets revealed that the fall jet extended for longer duration than the spring jet. The equatorial Kelvin wave with a wavelength of $\sim 1100 \mathrm{~km}$ was identified. Westward propagating Rossby wave was identified at $5^{\circ} \mathrm{N}$ more clearly. The zonal currents at $5^{\circ} \mathrm{N}$ (south of Sri Lanka) revealed intense anticyclonic (cyclonic) eddy activity between $75^{\circ}$ and $80^{\circ} \mathrm{E}$ during summer (winter) monsoon.
\end{abstract}

Key words: Wyrtki jet, Equatorial Indian Ocean, sea level anomaly, altimetry, surface currents, Kelvin wave, Rossby wave, interannual variability, Acoustic Doppler Current Profiler and OFES simulations.

\section{INTRODUCTION}

Currents in the Indian Ocean are driven mainly by the seasonal monsoon winds viz., northeast monsoon and southwest monsoon. However, during the intermonsoon periods (April - May and October - November) the winds over the equatorial Indian Ocean (EIO) are mainly westerly and thereby generate strong equatorial jets, known as Wyrtki Jets [1]. The surface currents in the EIO are dominated by a semi-annual component and reverse direction four times a year $[2,3]$. The currents in the EIO flow westward during winter and summer and eastwards during April-May (spring) and October-November (fall) transitions. The generating processes of these equatorial jets, such as, the direct forcing by the wind, reflected Rossby waves, resonance, mixed layer shear, and the influence of the Maldive Islands have been examined [3]. The interannual variability in the semiannual Jets results from the variability in the eastward equatorial winds along the equator. The equatorial zonal wind stress component and the monsoon current regions vary strongly with the El Nino Southern Oscillation (ENSO) phenomena with weaker (stronger) winds during El Nino (La Nina). Besides, the existence of Indian Ocean Dipole Mode [4, 5, 6], which is independent of ENSO, could cause variations over interannual time scales. For example, the Ocean General Circulation Model (OCGM) simulations revealed that the eastward equatorial jets in the Indian Ocean were weak during 1994 [7]. Amplitudes of the spring and fall jets and the winter westward surface current (January-March) are reduced by as much as $15-25 \mathrm{~cm} \mathrm{~s}^{-1}$ [3]. The equatorial region also acts as a wave guide and the equatorially trapped waves play an important role in the adjustment of the ocean to the wind forcing. The direct wind forcing generates equatorial Kelvin and Rossby waves. The presence of the Sumatra coast and the adjoining islands piles up the water there at the east [1] which results change in the zonal slope of the mixed layer $[8,9]$. These waves reflect at the eastern and western boundaries and both processes are crucial to the circulation in the north Indian Ocean [10]. The reflection and resulting resonance are responsible to the simulated large semiannual harmonic at the equator [11, 12]. The Equatorial Jets and the propagating waves advect both heat and salt towards east and thereby change the upper ocean heat and salt budgets leading to climate variability in the region.

*yksoma@nio.org; phone +91 8322450 222; fax +91 8322450 608; www.nio.org

Remote Sensing of the Marine Environment, edited by Robert J. Frouin, Vijay K. Agarwal,

Hiroshi Kawamura, Shailesh Nayak, Delu Pan, Proc. of SPIE Vol. 6406, 640617, (2006)

0277-786X/06/\$15 doi: $10.1117 / 12.693802$

Proc. of SPIE Vol. 6406 640617-1 
Measurements of currents along the equator in the equatorial Indian Ocean have been taken up as part of the Department of Ocean Development project at $\mathrm{NIO}$ wherein a long time series data from 3 moorings at locations $93^{\circ} \mathrm{E}, 83^{\circ} \mathrm{E}$ and $77^{\circ} \mathrm{E}$ from 2000 to 2004 were generated. Besides these, participation of researchers from JAMSTEC, Japan in the atmospheric and ocean observations from the EIO also enhanced the time series measurements. Studies based on these time-series data from moorings, indicated the intra-seasonal (biweekly period) variability in the measured currents and also in the model simulations $[13,14,15,16]$. The time series currents data point out that the semi-annual variability is dominant in zonal currents in the eastern equatorial Indian Ocean. With the deployment of ADCP moorings, new information is emerging on the intra-seasonal variability in the zonal currents, particularly during periods when the equatorial jet is active.

Satellite altimetry gives an opportunity to study the extent, intensity and variability in the Equatorial jets at seasonal and interannual time scales. In the present study, the interannual variability of the equatorial Jets has been examined through the analysis of the merged ERS-1/2, TOPEX/POSEIDON and Jason-1 altimeter data [17]. Also used in this study are the QuikSCAT derived sea surface winds and zonal wind stress to examine the interannaul variability in the wind forcing.

\section{DATA}

\subsection{Sea level anomaly data}

The high spatial and temporal coverage of satellite altimetry provides an excellent opportunity to study mesoscale structures. In order to obtain a better resolution, it was found essential to use the merged multi-satellite altimeter data sets $[17,18]$. In this study, the gridded product of merged ERS-1/2, TOPEX/POSEIDON and Jason-1 sea level anomaly (SLA) weekly Global data sets starting from January 1997 to December 2005 period distributed on a $1 / 3^{\circ}$ x $1 / 3^{\circ}$ Mercator grid and also available from August 2001 onwards on the live access server at [http://www.aviso.oceanobs.org] are utilized. Sea level anomalies are relative to a long term mean (say, calculated over the period 2002-2005). The mapping methods used to process the data and reduce the errors are given in detail [17]. The merged data set provides more homogeneous and reduced mapping errors than either of the individual data set, yielding more realistic sea level and geostrophic current. As the resolution of the gridded data is of order 30-35 km, the SLA variations at $50 \mathrm{~km}$ wavelength have their energy reduced by $50 \%$ [17], this data set can be used to study eddies and current systems having diameters larger than $70 \mathrm{~km}$, corresponding to the Rossby radius for the region [19].

\subsection{Wind stress data}

QuikSCAT mean wind field is a continuation of the effort of CERSAT to produce global wind fields from various scatterometers. The QuikSCAT MWF product provides daily, weekly and monthly wind fields over global $0.5^{\circ} \mathrm{x} 0.5^{\circ}$ resolution geographical grids. Main parameters include wind speed (module, divergence and components), wind stress (magnitude, curl and components). In order to reconstruct gap-filled and averaged synoptic fields from discrete observations over each time period, a statistical interpolation is performed using an objective method; the standard errors of the parameters estimated by this method are also computed and provided as complementary gridded fields [20]. Wind divergence and stress curl are also derived respectively from wind and stress grids and included in the dataset. The QuikSCAT weekly wind fields available from mid 1999 onwards at CERSAT site [http://www.ifremer.fr/cersat/] are downloaded and used in this study.

\section{METHODOLOGY}

\subsection{Computation of geostrophic current velocity field from the merged altimetry datasets}

To derive the near surface circulation through synthesis of altimetry derived quasi-geostrophic flows, a geostrophic current is computed from the sea level gradients. The difficulty of computing geostrophic current at the equator was treated by devising a weighted blend of the equatorial beta-plane and conventional f-plane geostrophic equations (also described in [21]. Considering the geostrophic balance, residual sea surface velocity components were calculated from the SLA data sets, using the geostrophic relation [22].

$$
u=-\frac{g}{f} \frac{\partial h}{\partial y}
$$

Proc. of SPIE Vol. 6406 640617-2 


$$
v=\frac{g}{f} \frac{\partial h}{\partial x}
$$

where $h$ is the SLA, $u$ and $v$ are the zonal and meridional components of velocity, $g$ is acceleration due to gravity, $f$ is the Coriolis parameter, and $\partial x$ and $\partial y$ are the eastward and northward distances of the grid.

By differentiating the geostrophic equations $(1,2)$ we obtain a finite value of the velocities at the equator $(3)$.

$$
\left.u\right|_{y=0}=-\frac{g}{\beta} \frac{\partial^{2} h}{\partial y^{2}}
$$

Picaut and Tournier [23] also defined a "corrected" SLA (4) to assure nonsingularity of (1).

$$
\begin{gathered}
\qquad h_{c}(y)=h(y)+h^{\prime}(y) \\
\text { where } \quad h^{\prime}(y)=A y \exp \left(-y^{2} / L^{2}\right) \\
\text { and } \quad A=-\left.\frac{\partial h}{\partial y}\right|_{y=0}
\end{gathered}
$$

So with the "corrected" SLA, the geostrophic velocities have been estimated from (1) away from the equator and from (3) on the equator.

The equation (3) was used to compute the geostrophic currents in the $2^{\circ} \mathrm{S}-2^{\circ} \mathrm{N}$ belt and the equations (1) and (2) for the grids beyond $2^{\circ} \mathrm{N}$ and $2^{\circ} \mathrm{S}$.

\subsection{Analysis of QuikSCAT winds}

The QuikSCAT weekly wind fields at $0.5^{\circ} \times 0.5^{\circ}$ resolution from January 2000 to December 2004 are used to compute monthly mean wind stress fields and are used to prepare plots of annual cycle at six locations along the equator similar to that of SLA.

\section{RESULTS AND DISCUSSION}

\subsection{Seasonal variation of Sea level anomaly}

In this study, the sea level anomalies at $50^{\circ}, 60^{\circ}, 70^{\circ}, 77^{\circ}, 83^{\circ}$ and $93^{\circ} \mathrm{E}$ along the equator are analyzed to examine their seasonal variations in relation to the zonal currents, while the presentation is limited to $60^{\circ}, 77^{\circ}$ and $93^{\circ} \mathrm{E}$ (Fig. 1) representing the western, central and eastern equatorial basins. A considerably larger bin area of $2^{\circ} \times 2^{\circ}$ was chosen to construct the spatial mean of SLA from the available closely spaced $\left(1 / 3^{\circ} \times 1 / 3^{\circ}\right)$ SLA grids. For example, the mean sea level at $60^{\circ} \mathrm{E}$ is based on all grid values between $59^{\circ}$ and $61^{\circ} \mathrm{E}$ and between $1^{\circ} \mathrm{S}$ and $1^{\circ} \mathrm{N}$. Fig. 1 depicts plots for the three locations $\left(60^{\circ}, 77^{\circ}\right.$ and $\left.93^{\circ} \mathrm{E}\right)$ for all the 9 years between 1997 and 2005. Each subplot comprises of three curves representing three consecutive years. Keeping the intense El Nino and the Indian Dipole Mode event (IOD) during 1997-98 in mind, the subplots for 1997, 1998 and 1999 are shown separately. In the western basin $\left(60^{\circ} \mathrm{E}\right)$, in all the 9 years examined, the SLA is more negative during January - March in each year. During the IOD event, negative SLA prevails during October - December in 1997. During April - September, the SLA is weakly positive, including the period of IOD event. In the central basin $\left(77^{\circ} \mathrm{E}\right)$, the occurrence of relatively higher positive SLA during April - August, is conspicuous, when compared to those in the western basin. During the IOD event, the SLA attains larger positive values. When one moves towards the eastern basin, i.e., at $93^{\circ} \mathrm{E}$, the SLA variation is large with larger positive and negative values $( \pm 20 \mathrm{~cm})$. In this basin, the SLA exhibits a pronounced semi-annual variation, in contrast to those in the western and central basins. The impact of IOD event is more evident in the eastern basin and extended to longer duration from April 1997 to December 1998. 


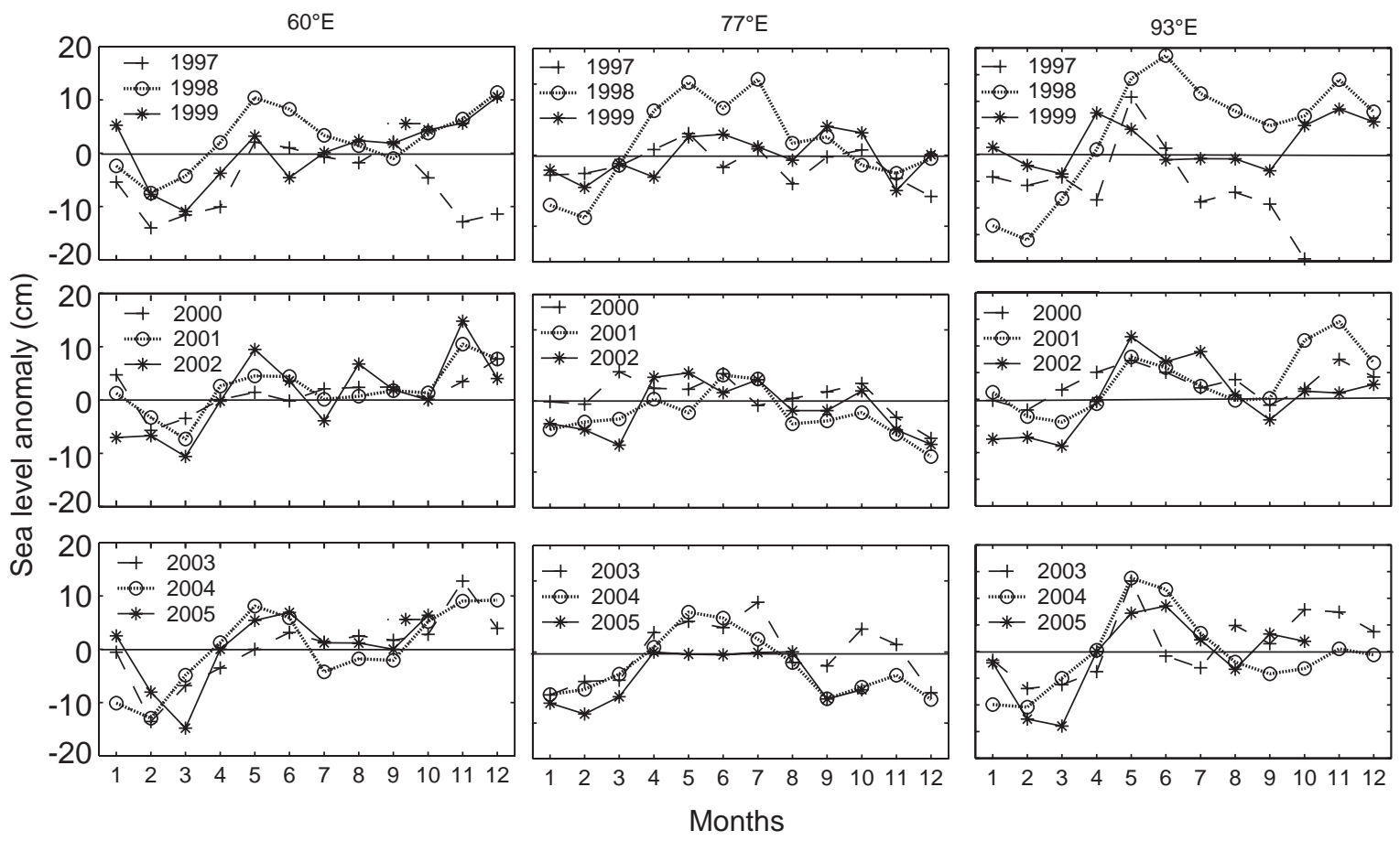

Fig. 1. Seasonal Cycle of Sea level anomaly at $60^{\circ} \mathrm{E} ; 77^{\circ} \mathrm{E}$ and $93^{\circ} \mathrm{E}$ along equator.

\subsection{Comparison of SLA derived zonal currents with observations and model simulated currents.}

Fig. 2 depicts the monthly variation of zonal velocity in the equatorial Indian Ocean at equator, $77^{\circ} \mathrm{E}$ during September 2001 to December 2004 as derived from merged altimetry (using equation 3), OGCM for Earth Simulator (OFES) simulated currents at $2.5 \mathrm{~m}$ depth at the same location for the same period and ADCP measured currents at $38 \mathrm{~m}$ depth (equator, $77^{\circ} \mathrm{E}$ ) for the period September 2003 - October 2004. The altimetry derived currents are found to match with the observations and model simulations. However, one can notice large magnitudes of zonal velocity in the altimeter derived currents in some months. Discrepancy is also noticed between altimeter derived currents and measured currents especially in May 2004 and October 2004. This may be due to the fact that measured currents are from $38 \mathrm{~m}$ depth. Discrepancy is also noticed between SLA derived currents and OFES currents particularly in 2002 which is an anomalous monsoon year. However, all the zonal currents clearly indicate the semi-annual variation with maximum eastward current during spring and fall and westward current during winter and southwest monsoon months. Following this encouraging exercise of comparison of currents at equator, $77^{\circ} \mathrm{E}$, we assume that the Eq. (3) can be applied for estimation of zonal currents all along the equator.

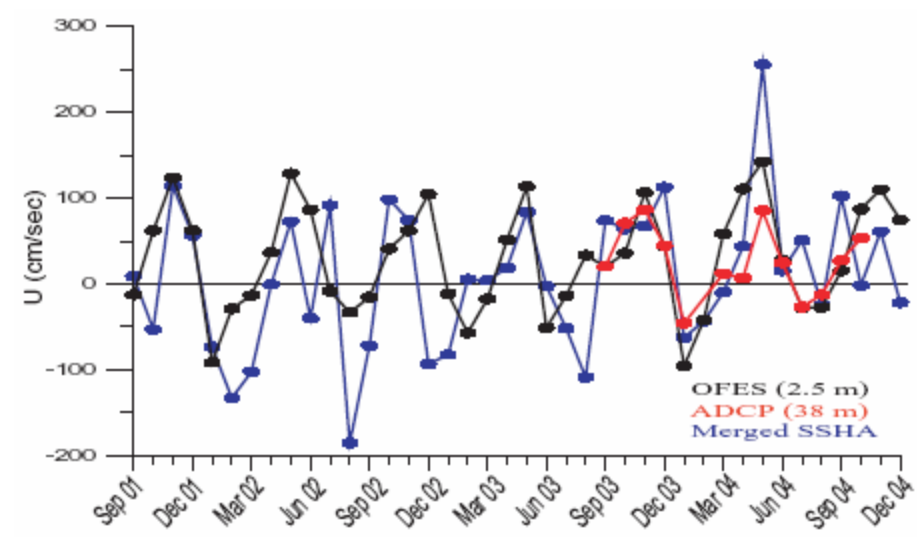

Fig. 2. Comparison of zonal currents at equator, $77^{\circ} \mathrm{E}$ derived from merged altimetry, insitu observations and models. 


\subsection{Seasonal variation of estimated zonal currents in the equatorial Indian Ocean}

Fig. 3 shows the estimated zonal currents at the selected locations in the western, central and eastern basins. Out of the three locations, semi-annual variability with two peaks of eastward currents corresponding to boreal spring and fall equatorial jets and two peaks of westward current during winter and summer months is more conspicuous at $77^{\circ} \mathrm{E}$ during

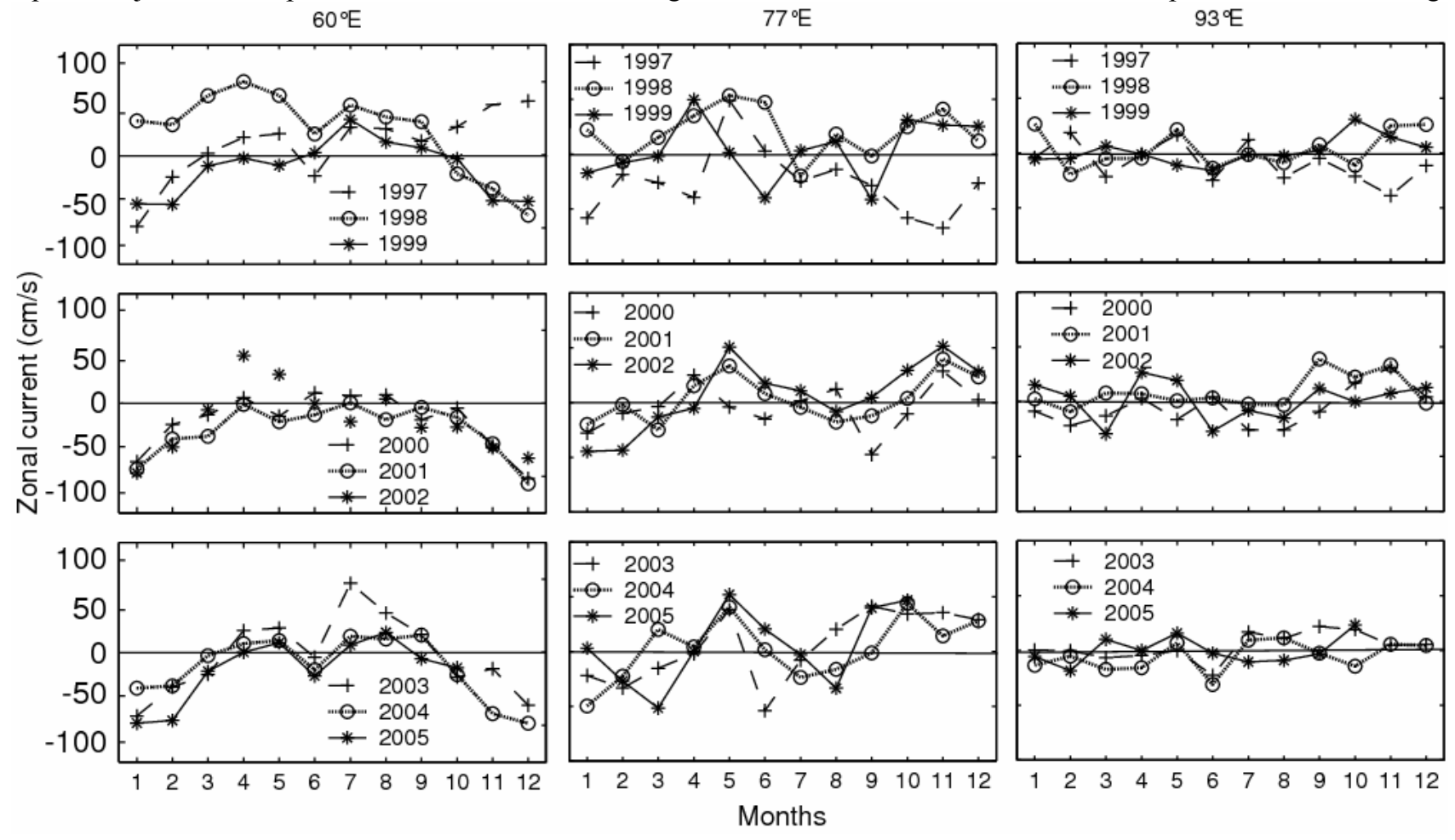

Fig. 3. Seasonal cycle of zonal currents along equator at $60^{\circ} \mathrm{E}, 77^{\circ} \mathrm{E}$ and $93^{\circ} \mathrm{E}$.

$1998,2000-05$. The monthly variations of zonal current at $93^{\circ} \mathrm{E}$ shows weaker semi-annual variation in all the 9 years. Interannual variability in the zonal current is more evident at $60^{\circ} \mathrm{E}$ and $77^{\circ} \mathrm{E}$ during $1997-98$ when the Indian Ocean Dipole Mode event occurred. In the western basin, the winter westward current and spring eastward current are clearly seen. During fall 1997 and spring 1998, throughout the equatorial Indian Ocean the flow is westward as a consequence of the strong El Nino/IOD event. The Wyrtki Jet in all the other years portrayed an organized eastward flow. West of $77^{\circ}$ E, a strong westward flow was observed with average magnitudes reaching over $50 \mathrm{~cm} / \mathrm{s}$ between February and April in all the years. The core region of the equatorial Jets exists between $70^{\circ}$ and $80^{\circ} \mathrm{E}$ where the average magnitudes of eastward currents exceed $50 \mathrm{~cm} / \mathrm{s}$ with relatively higher values occurring during fall transition as seen at $70^{\circ} \mathrm{E}$ during 2003, 2004 and 2005. Towards the eastern equatorial region, the magnitudes show a gradual decrease as clearly seen at $93^{\circ} \mathrm{E}$.

\subsection{Inter annual variability}

Intra-seasonal to interannual variability has a big effect on climate change. Large-scale intra-seasonal sea level variability (10-100 days) is mainly driven by oscillations that are coherent over thousands of kilometers and are a direct response of high frequency wind forcing. El Nino events, including the strong 1997-98 event are dramatic example of interannual changes corresponding to the strong ocean-atmosphere interactions. Other oscillations at periods longer than 100 days are due to propagation of Rossby waves across the ocean basins.

The mean monthly maps of SLA based on the averages of 1997-2005, excluding the anomalous ENSO/IOD feature of 1997-98 (from fall 1997 to spring 1998) are presented in Fig. 4 for the months of May and November along with the current vectors superimposed on these maps. It is evident from these plots that in the region of the eastern equatorial Indian Ocean (EEIO) near Sumatra, a strong positive SLA prevails, while the western equatorial Indian Ocean (WEIO) 
depicts either low positive (May) or a negative (November) SLA. The seasonal warming signal is evident in the northern part of the equator during boreal summer (May) and a cooling signal during November. A large positive SLA in the EEIO hugging the eastern boundary over a wider area during May is due to the termination of equatorial Kelvin wave at the eastern boundary and its poleward propagation as a coastally trapped wave along the eastern boundary (Sumatra coast). Fig. 4 depicts this classical view of equatorial Kelvin wave and the associated onset of westward propagating reflected Rossby wave along the equator and radiating Rossby waves (which propagate westward) from the eastern boundary. This is manifested as larger cells of higher positive SLA on either side of the equator. These cells move westward and appear as meso-scale eddies. The presence of an anticlock wise circulation to the north of equator and a clock-wise circulation to the south of equator (both are low sea level anomaly regions) in the western region favours eastward flow hence stronger Wyrtki Jet during boreal fall season as seen clearly from mean November map (Fig. 4).
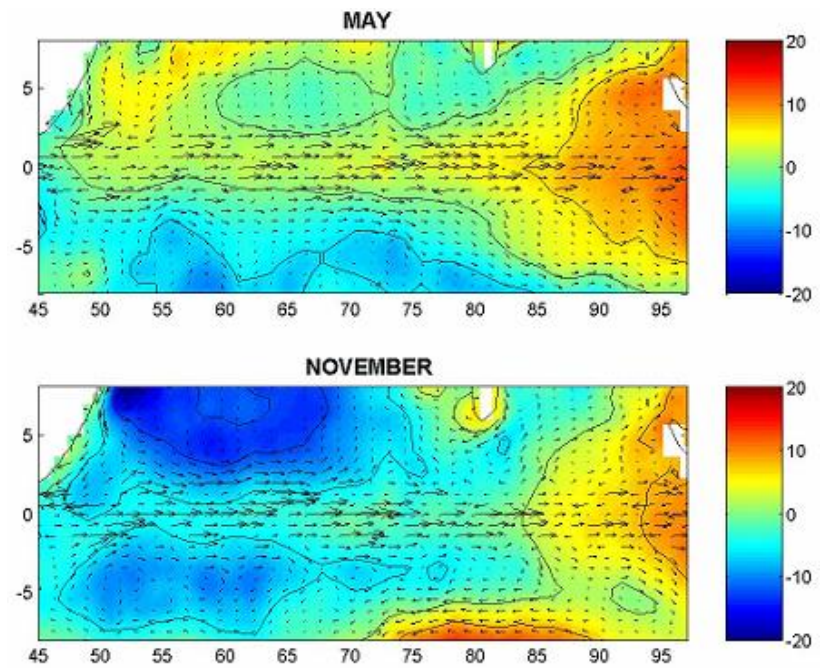

Fig. 4. Sea level anomaly and current vector maps (mean 1998-2005) for May (spring) and November (fall) months.

The May and November distributions for the individual years are examined. Besides depicting the deviation of sea level anomaly for May and November of individual years (after removing the 9 year mean) along with the equatorial currents during transition periods, Fig. 5 also reveals the signatures of equatorial Kelvin wave and westward propagating Rossby
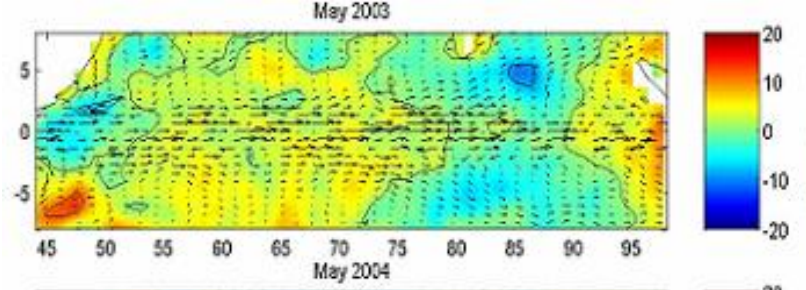
NONEMBER 2003
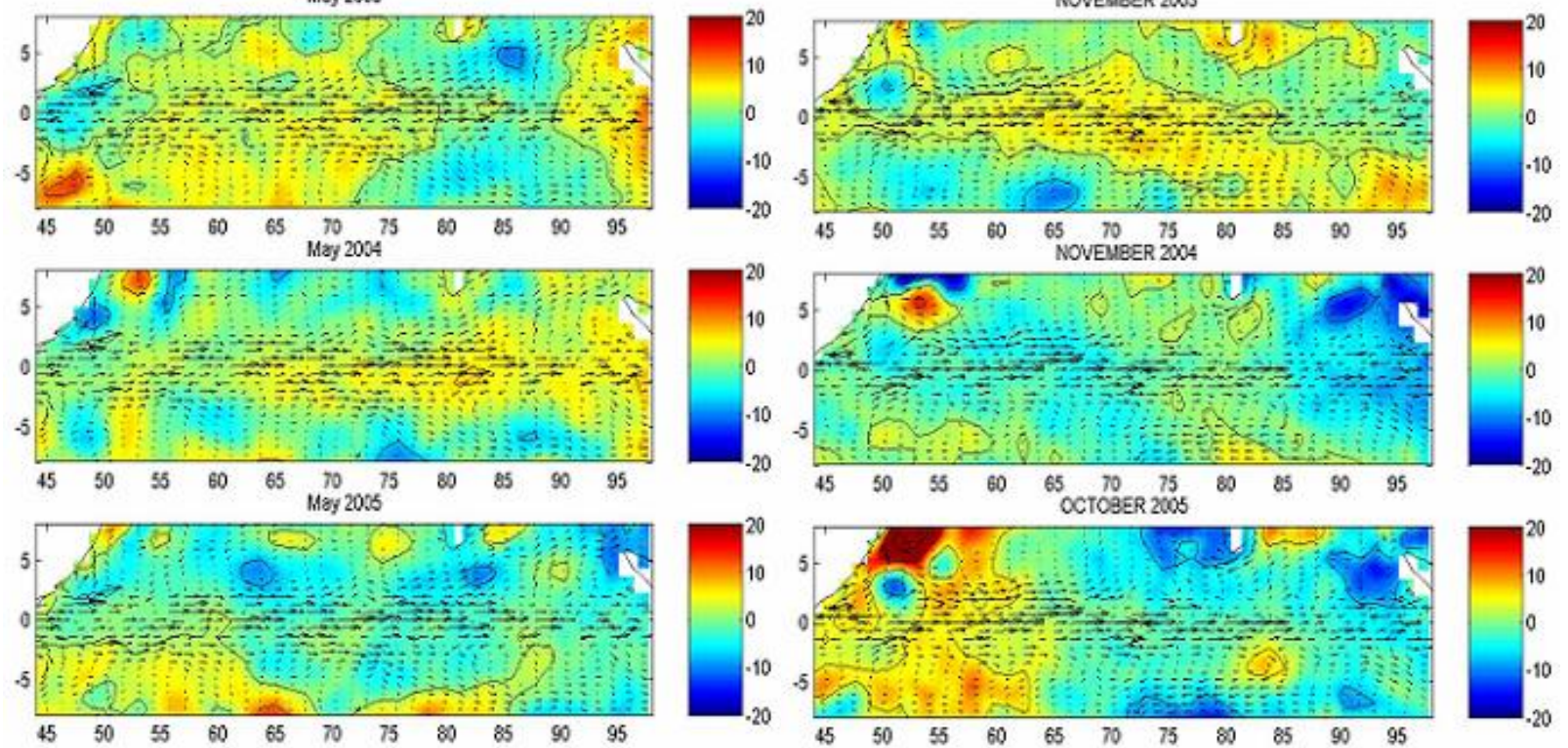

Fig. 5. Interannual variation of zonal currents (with sea level anomaly superimposed) for May and November 2003, 2004 and 2005 . 
wave. The maps corresponding to May 2003 and November 2004 display positive and negative sea level anomaly features respectively on to both northern and southern sides of the equator in the eastern equatorial region (east of $80^{\circ} \mathrm{E}$ ). Kelvin waves on reaching the eastern margin of the equatorial Indian Ocean get reflected/ refracted. While the refracted wave propagates as a coastal trapped Kelvin wave to the north and to the south of the equator, the reflected Kelvin wave undergoes upwelling/ downwelling depending on the phase of the wave and converts in to a Rossby wave that propagates westward in the reverse direction. Similar features are also evident during the months of May 2000, 2002 and 2003.

In order to identify the significant features of the interannual variability of the Wyrtki Jets in the vicinity of the equator in the Indian Ocean, the zonal currents computed for all the months between 1997 and 2005 are arranged in different rows to form a matrix with longitude on $\mathrm{x}$-axis and time in months on $\mathrm{y}$-axis and the current magnitudes are contoured. The rows corresponding to the months November and December, 2005 in these plots are blank due to SLA data gap. The eastward (positive) currents are represented in red while the westward (negative) currents are shown in blue. The longer duration of the fall jet over the spring jet in all the years of observation is clearly visible in this plot (Fig. 6). The Wyrtki Jets are strong between $60^{\circ}$ and $80^{\circ} \mathrm{E}$. By closely observing this diagram, it is possible to identify the Kelvin wave crests which have a spatial length scale of about $10^{\circ}(1100 \mathrm{~km}$ approx.).

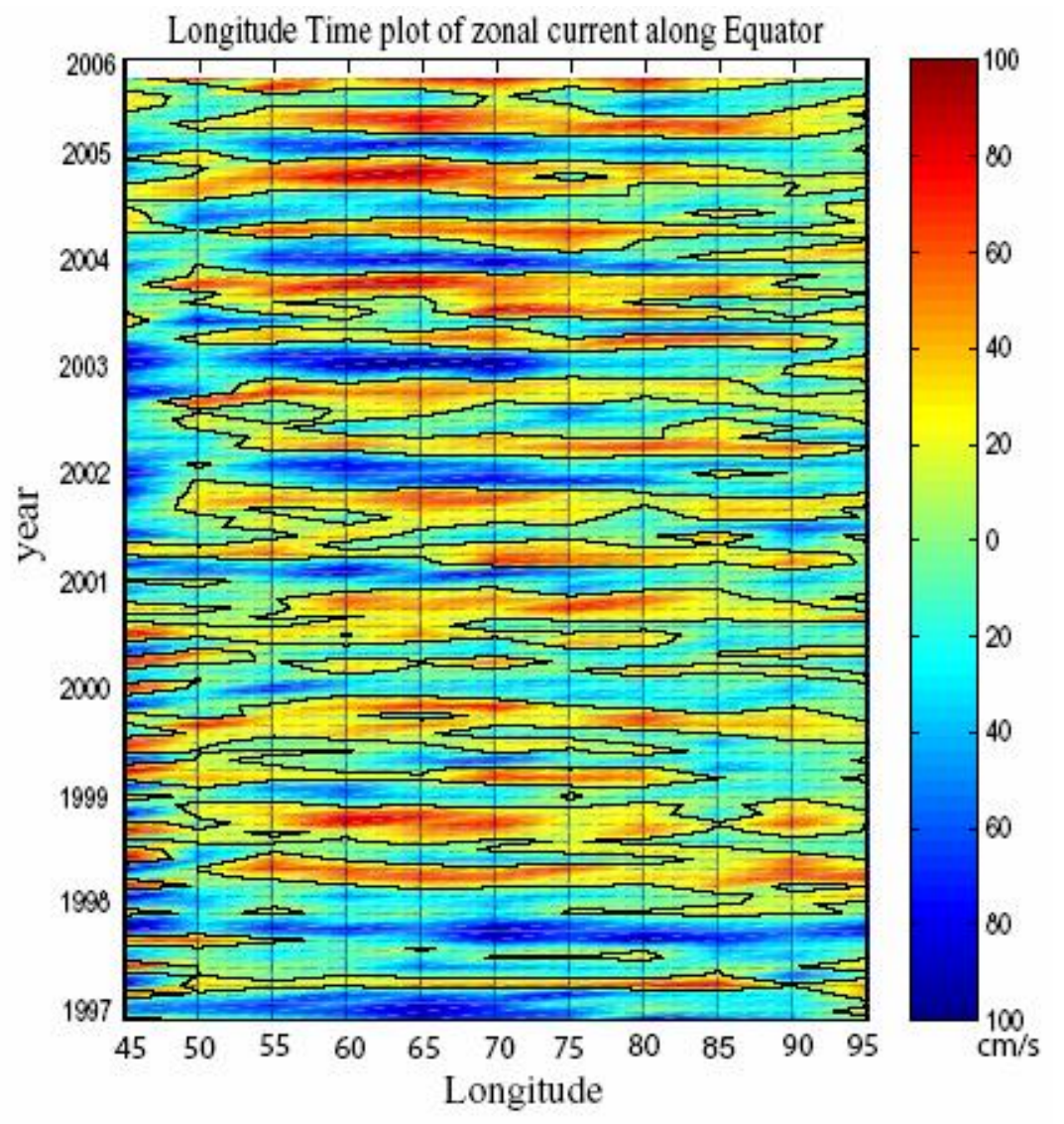

Fig. 6. Longitude-time plot of zonal currents at the equator

\subsection{Interannaul variability of zonal wind stress and SLA}

To study the relation between the sea level variations and the wind stress variations in the equatorial Indian Ocean, the QuikSCAT wind stress data from January 2000 to December 2004 have been analyzed at three locations to match with the SLA field and are shown in Fig. 7. In all the years the eastward zonal wind stress is high (positive) at $77^{\circ} \mathrm{E}$ for longer duration (late March/early April to November/early December) during 2000-02. Large negative wind stress due to prevailing unusual easterlies prevailed at $93^{\circ} \mathrm{E}$ in 2002 during August - November, 2002, compared to the other locations. This is an anomalous feature in the eastern basin, and its impact on the Indian monsoon activity (draught 
situation over India) has been reported [24]. During the positive regime at $77^{\circ} \mathrm{E}$ during $2000-02$, three peaks of positive wind stress are noticed. Semi-annual variation of zonal wind stress with two positive peaks in spring and fall and negative peaks during southwest and northeast monsoons is evident at $60^{\circ} \mathrm{E}$ during $2000-04$ (left panel in Fig. 7). The variability of wind stress to the west of $65^{\circ} \mathrm{E}$ is within $5.0 \times 10^{-4} \mathrm{~N} \mathrm{~m}^{2}$ while to the east of $65^{\circ} \mathrm{E}$, it is higher up to $1.0 \times 10^{-3}$ $\mathrm{N} \mathrm{m}^{2}$. It is noticed that positive wind stress field covers a larger part of the region east of $75^{\circ} \mathrm{E}$.
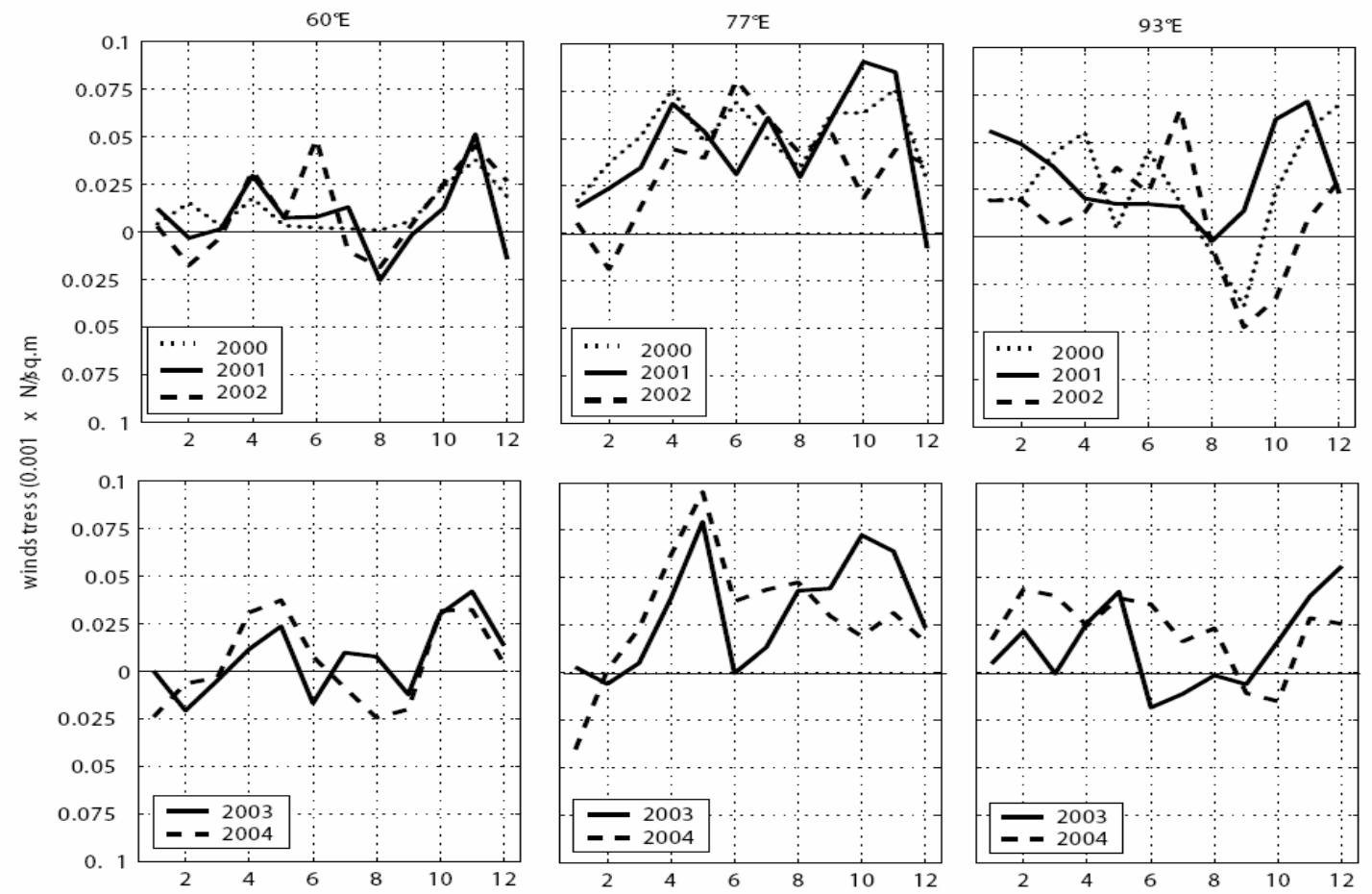

Fig.. 7. Seasonal cycle of zonal wind stress $\left(\times 10^{-3} \mathrm{x} \mathrm{N} / \mathrm{m}^{2}\right)$ along equator at $60^{\circ} \mathrm{E}, 77^{\circ} \mathrm{E}$ and $93^{\circ} \mathrm{E}$
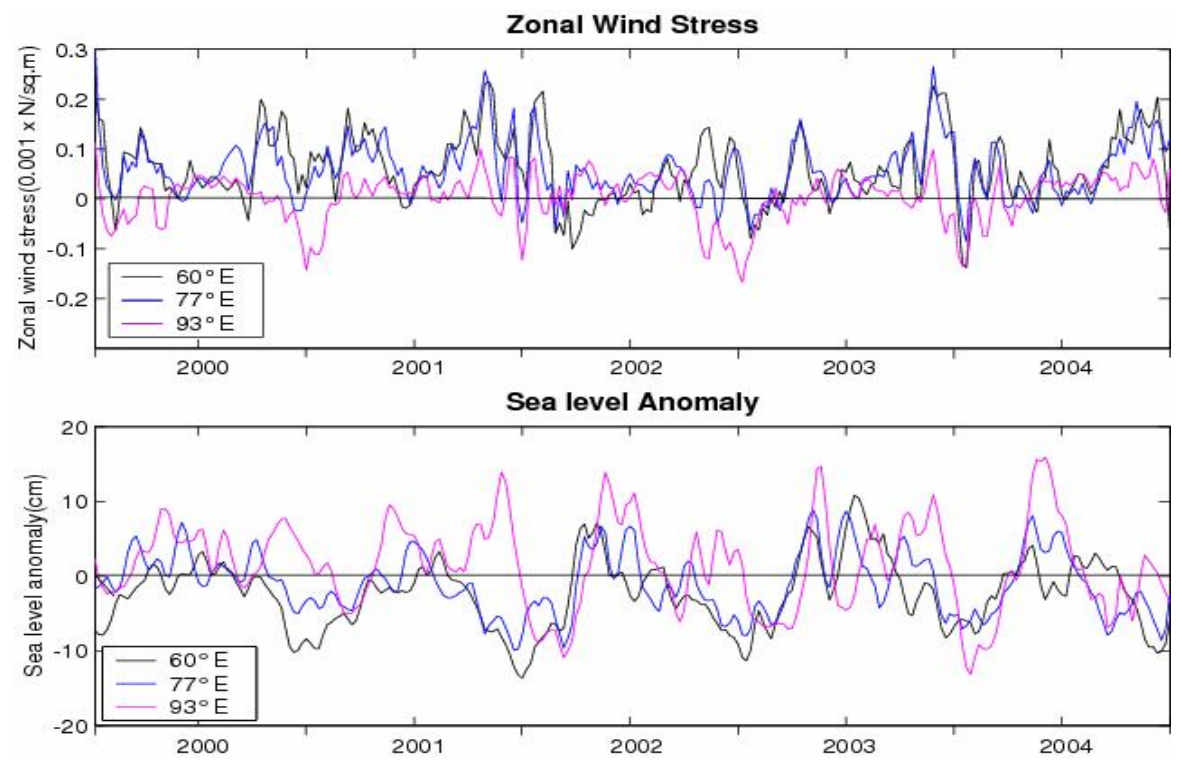

Fig. 8. Interannual variation of (a) zonal wind stress, and (b) SLA at $60^{\circ}, 77^{\circ}$ and $93^{\circ} \mathrm{E}$ along the equator. The year numbers are given at the middle of the year. 
Semi-annual variation of zonal wind stress is not clear at $77^{\circ} \mathrm{E}$ during $2000-03$, but some indication is seen in 2004 . Similarly, semi-annual variation of zonal wind stress is weakly evident at $93^{\circ} \mathrm{E}$. Fig. 8 shows the interannual variation of zonl wind stress at the three locations (as that presented in Fig. 7) and the corresponding variation in SLA at the same locations. It is noticed that eastward wind stress (positive) is dominant both at $60^{\circ}$ and $77^{\circ} \mathrm{E}$ and westward wind stress (negative) occurred at $93^{\circ} \mathrm{E}$ in some years. Positive (negative) SLA corresponds to the eastward (westward) wind stress. The positive (negative) SLA deepens (shoals) the thermocline, thus SLA variability is connected to the upper ocean processes. The positive SLA during spring season is comparable at all the three locations, with a peak value at $93^{\circ} \mathrm{E}$. However, the SLA at $93^{\circ} \mathrm{E}$ during fall season is opposite to that at $60^{\circ} \mathrm{E}$ and $77^{\circ} \mathrm{E}$, particularly during $2000-03$. In early 2004, negative SLA occurs at all the locations indicating the shallowing of thermocline at all the three locations.

\subsection{Observation on Rossby wave propagation}

To observe Rossby wave propagation in the region away from the equator, longitude - time sections of zonal current at $5^{\circ} \mathrm{N}$ and $5^{\circ} \mathrm{S}$ are presented in Figs. 9a-b. It may be noted that data gap in SLA caused data gap in zonal currents for the period November - December 2005 in these plots. The upward slope towards west in both negative (blue) and positive (red) bands indicate the westward propagation of Rossby waves. It takes almost a year for a Rossby wave to travel westwards covering a distance of $4950 \mathrm{~km}$ from $95^{\circ} \mathrm{E}$ to $50^{\circ} \mathrm{E}$ with speed of $15 \mathrm{~km} /$ day $(\sim 16 \mathrm{~cm} / \mathrm{s})$. Similar propagating signatures are also observed at $5^{\circ} \mathrm{S}$ with slightly lesser propagation speeds. Associated with the Rossby wave propagation at $5^{\circ} \mathrm{N}$, an intense eddy activity, with alternate cyclonic (anticyclonic) eddies, can be inferred during summer (winter) monsoon between $75^{\circ}$ and $80^{\circ} \mathrm{E}$ (south of Sri Lanka). Similar patterns with lesser intensity are evident from $5^{\circ} \mathrm{S}$ section.

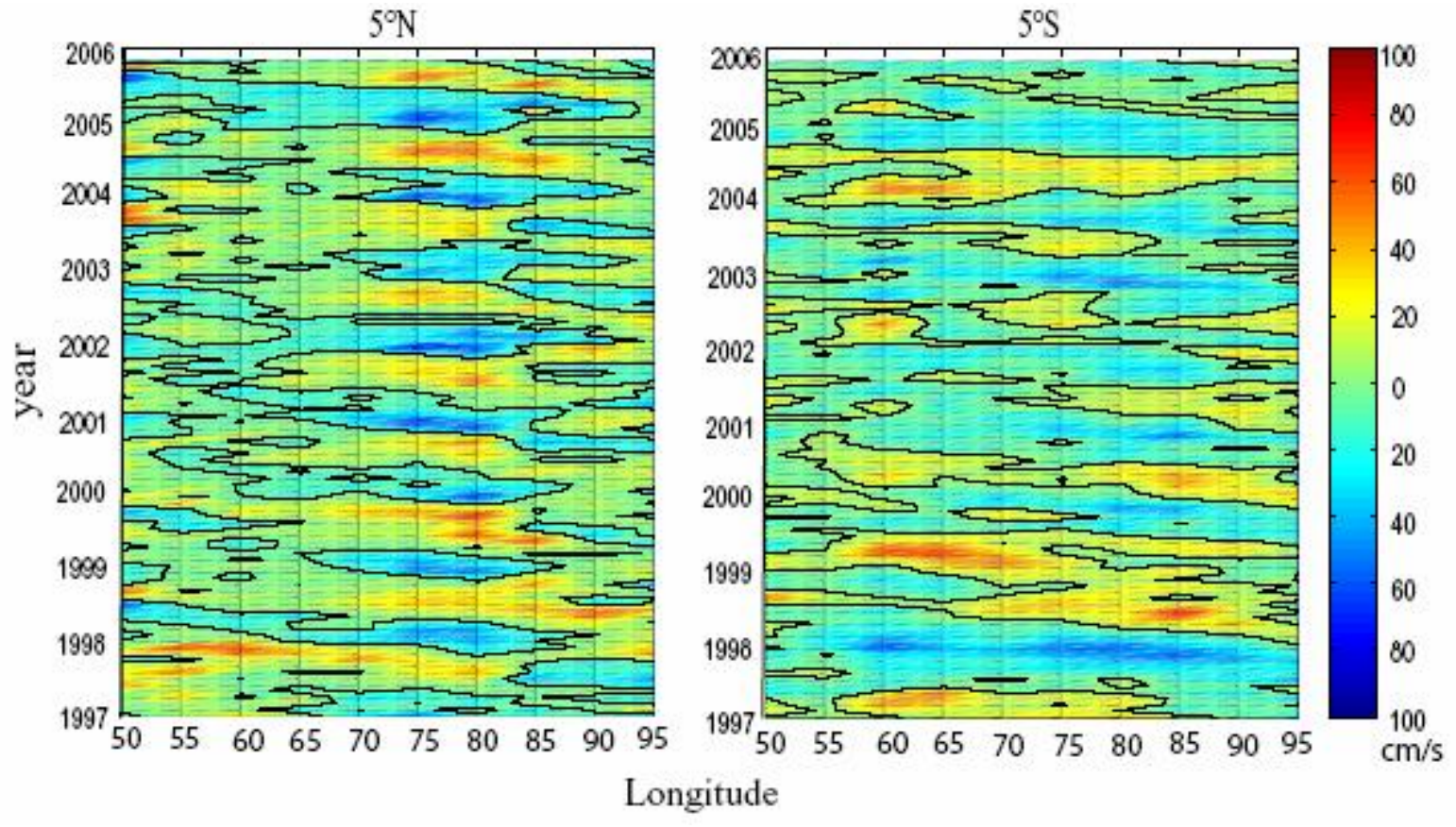

Fig. 9. Longitude-time plot of zonal currents depicting Rossby wave propagation at $5^{\circ} \mathrm{N}$ and $5^{\circ} \mathrm{S}$

\section{CONCLUSIONS}

The nature and variability of the equatorial jets in the Indian Ocean are analyzed using the merged ERS-1/2, TOPEX/POSEIDON and Jason-1 altimeter data sets. Eastward flowing semi-annual equatorial jets are forced by the eastward zonal wind stress of semi-annual period (April/May and October/November). These jets force the upper thermocline to deepen towards east along the equator causing the propagation of low-frequency Kelvin waves in the equatorial Indian Ocean. The presence of equatorial Kelvin wave of wavelength $\sim 1100 \mathrm{~km}$ has been identified, while westward propagating Rossby wave signatures are identified at $5^{\circ} \mathrm{N}$ and $5^{\circ} \mathrm{S}$. These Kelvin waves impinging upon the eastern boundary radiate westward propagating Rossby waves, under whose influence the SLA deepens in the eastern basin. The present analysis clearly identified these features and highlighted that SLA variability is large in May in the 
eastern basin $\left(93^{\circ} \mathrm{E}\right)$, while zonal currents are strong during November in the western $\left(60^{\circ} \mathrm{E}\right)$ and central $\left(77^{\circ} \mathrm{E}\right)$ basins. Apart from the 1997-98 IOD event, interannual variations in SLA and zonal currents are also noticed in 2002 when the zonal winds over the equatorial Indian Ocean were unusual. The altimeter derived surface currents are in good agreement with the moored Acoustic Doppler Current Profiler (ADCP) measured currents and model simulations.

\section{ACKNOWLEDGEMENTS}

The authors wish to thank the Director, National Institute of Oceanography for his interest in this study. Thanks are also due to AVISO, France and CERSAT, France for providing the merged weekly products of altimeter data and QuikSCAT data through their web sites. The OFES simulations for the period September 2003 - October 2004 were provided by Dr. Yukio Masumoto, University of Tokyo, Japan under the NIO-JAMSTEC collaboration MoU. The Matlab routine for computing currents close to the equator has been developed by Mr. Vincent Moutel, an Engineering student from Superior Institute of Engineering Sciences of Toulon, France for his project work carried at NIO during 2005. This has NIO contribution No. XXXXX.

\section{REFERENCES}

1. K. Wyrtki, “An equatorial jet in the Indian Ocean.”, Science, 181, 262-264 (1973).

2. M.Tomczak and J.S. Godfrey, Regional Oceanography, Pergamon press, 1999.

3. W. Han, J.P. McCreary, D.L.T. Anderson and A.J. Mariano, "On the dynamics of the eastward surface jets in the equatorial Indian Ocean", J. Phys. Oceanogr., 29, 2191-2209 (1999).

4. N.H. Saji, B.N. Goswami, P.N. Vinayachandran and T. Yamagata, "A dipole mode in the tropical Indian Ocean", Nature, 401, 360-363 (1999).

5. P.J. Webster, A.M. Moore, J. Loschnigg and R.R. Leben, "Coupled Ocean-Atmosphere Dynamics in the Indian Ocean during 1997-98", Nature, 401, 356-360 (1999).

6. J. Reppin, F.A. Schott and J. Fischer, "Equatorial currents and transport in the upper central Indian Ocean: Annual Cycle and interannual variability", Journal Geophysical Research, 104 (C-7), 15495-15514 (1999).

7. P.N.Vinayachandran, N.H. Saji, and T.Yamagata, "Response of the Equatorial Indian Ocean to an unusual wind event during 1994", Geophysical Research Letters, 26, No. 11, pp.1613-1616 (1994).

8. J.J. O'Brien and H.E. Hulburt, "Equatorial Jet in the Indian Ocean: Theory", Science, 184, 1075-1077 (1974).

9. M.M. Ali and R. Sharma, "Inference of the reversal of mixed layer zonal slope along the equatorial Indian Ocean using Geosat altimeter data", International Journal of Remote Sensing, 14, 2043-2049 (1993).

10. J.P. McCreary, P.K. Kundu, and R.L. Molinari, "A Numerical investigation of the dynamics, thermodynamics and mixed layer processes in the Indian Ocean", Progress in Oceanography, 31,181-244 (1993).

11. T.G. Jensen, "Equatorial variability and resonance in a wind-driven Indian Ocean model", J. Geophys. Res., 98, 22533-22552 (1993).

12. D. Shankar, P.N.Vinayachandran, and A. S. Unnikrishnan, "The monsoon currents in the North Indian Ocean", Progress in Oceanography, 52, 63-120 (2002).

13. Y. Masumoto, V.S.N. Murty, M. Jury, M.J. McPhaden, P. Hacker, J. Vialard, R. Molcard, and G. Meyers, Tropical Indian Ocean mooring array: Present status and future plans, IOGOOS Report, 2002.

14. V.S.N. Murty, A. Suryanarayana, M.S.S. Sarma, V. Tilvi, V. Fernando, G. Nampoothiri, A. Sardar, D. Gracias, S. Khalap, "First results if Indian currentmeter moorings along the equator: vertical structure variability at equator, $93^{\circ}$ E during February-December, 2002", Proc. Pan-Ocean Remote Sensing Conf. PORSEC, held at Bali, Indonesia, 3-6 Dec. 2002, Vol.I, 25-28, 2002.

15. Y. Masumoto, H. Hase, Y. Kuroda, H. Matsuura, K. Takeuchi, "Intraseasonal variability in the upper layer currents observed in the eastern equatorial Indian Ocean", Geophys. Res. Lett., 32, L02607, doi:10.1029/2004GL021896, 2005.

16. D. Sengupta, R. Senan, V.S.N. Murty, V. Fernando, "A biweekly mode in the equatorial Indian Ocean”, J. Geophys. Res.,109, C10003,doi:10.1029/2004JC002329, 2004.

17. N. Ducet , P.Y. Le Traon, and G. Reverdine, "Global high-resolution mapping of ocean circulation from the combination of T/P and ERS-1/2", J. Geophys. Res., 105, 19, 477-19,498 (2000). 
18. P.Y. Le Traon, F. Nadal, and N. Ducet, "An improved mapping method of multisatellite altimeter data", J. Atm. Oceanic. Technol., 15, 522-533 (1998).

19. D.B. Chelton, R.A. de Szoeke, M.G. Schalax, , K. El Naggar, and N. Siwertz, "Geographic variability of the first baroclinic Rossby radius of deformation", J. Phys. Oceanogr., 28, 433-460 (1998).

20. Anonymous, QuikSCAT Scatterometer mean wind field products user manual, Réf.: C2-MUT-W-03-IF, Ver. : 1.0, 2002.

21. G. Lagerloef, S.E., Gary, T. Mitchum, R.B. Lukas and P. P. Niiler, "Tropical Pacific near-surface currents estimated from altimeter, wind, and drifter data", J. Geophys. Res., 104, 23,313-23,326, (1999).

22. D.B. Chelton, R.A. de Szoeke, M.G. Schalax, , K. El Naggar, and N. Siwertz, "Equatorially trapped Rossby waves in the presence of meridionally sheared baroclinic flow in the Pacific Ocean", Progress in Oceanography, 56, 323380 (2003).

23. J.Picaut and R. Tournier, "Monitoring the 1979-1985 equatorial Pacific current transports with expendable bathy thermograph data", J. Geophys. Res., 96, 3263-3277 (1991).

24. S. Gadgil, P. N. Vinayachandran and P.A. Francis, "Droughts of the Indian summer monsoon: Role of clouds over the Indian Ocean." Current Sci., 85(12), 1713-1719 (2003). 